\title{
Management of Neurobrucellosis: An Assessment of 11 Cases
}

\author{
Hanefi Cem Gul ${ }^{1}$, Hakan Erdem ${ }^{1}$, Levent Gorenek ${ }^{1}$, Mehmet Fatih Ozdag ${ }^{2}$, Yasin Kalpakci ${ }^{1}$, \\ Ismail Yasar Avci ${ }^{1}$, Bulent Ahmet Besirbellioglu and Can Polat Eyigun ${ }^{1}$
}

\begin{abstract}
Objective The central nervous system involvement of Brucellosis causes a hard to treat infection with multiple sequelae. The aim of this paper is to discuss the course of neurobrucellosis in response to therapy.

Patients and Methods Patients with neurobrucellosis were evaluated. The diagnosis was established by the isolation of bacteria, abnormal CSF findings and positive serology. Ceftriaxone, rifampicin, doxycycline and trimethoprim sulfamethoxazole were the antibiotic choices for these cases.

Results We present 11 cases with neurobrucellosis. None of our patients died, albeit one case has a critical situation due to subarachnoid hemorrhage and its' concordant sequelae. Only one of four patients with walking difficulty and two with hearing loss were normalized with therapy. Imaging techniques did not provide any specific contribution regarding the Brucella infection.

Conclusions Parenteral ceftriaxone should be used as an initial alternative in the management of neurobrucellosis. Although the therapy should be individualized, the duration of therapy should be a minimum of six months with suitable antibiotics.
\end{abstract}

Key words: neurobrucellosis, complications, therapy

(Inter Med 47: 995-1001, 2008)

(DOI: 10.2169/internalmedicine.47.0866)

\section{Introduction}

The genus Brucella causes the zoonotic infection brucellosis which was formerly known as undulant fever, Malta fever, Gibraltar fever, and Mediterranean fever (1). The disease is endemic in countries bordering the Mediterranean Sea and also occurs in many other countries $(2,3)$. Humans can acquire brucellosis by several routes (4): Direct inoculation through cuts and skin abrasions, especially from handling animal tissues or secretions, via the conjunctiva, inhalation of infected aerosols and ingestion of contaminated food such as raw milk, cheeses made from unpasteurized milk, or raw meat. Venereal transmission has been suggested, but the data are not conclusive (5).

The most common sites for localization of neurobrucellosis are osteoarticular, genitourinary, central nervous system (CNS), endocardium and liver. The clinical management of brucellosis is of particular concern due to the high initial treatment failure and relapse rates (6-8). The disease remains the world's most common bacterial zoonosis, with over half a million new cases annually; the prevalence rates in some countries exceed ten cases per 100,000 population (9).

The clinical spectrum of neurobrucellosis is very heterogeneous and can be categorized into central and peripheral forms (10). The former is commonly acute and results mainly in meningoencephalitis, while the latter may be either acute or chronic in presentation (11). Various presentations such as meningitis, encephalitides, polyradiculoneuritis, sensorial and motor abnormalities, cranial nerve involvement, epilepsy, depression, brain abscess, subarachnoid hemorrhage and finally coma are encountered (12). Hearing loss due to sensorioneural involvement is reported to be an important morbidity $(13,14)$. Less common neurological complications include papilledema, optic neuropathy, radiculopathy, stroke, and intracerebral hemorrhage (8). Accordingly,

${ }^{1}$ Department of Infectious Diseases and Clinical Microbiology, Gulhane Military Hospital, Ankara, Turkey and ${ }^{2}$ Department of Neurology, Gulhane Military Hospital, Ankara, Turkey

Received for publication March 3, 2008; Accepted for publication December 29, 2008

Correspondence to Dr. Hanefi Cem Gul, hcgul@yahoo.com 
Table 1. The Biochemical Analyses of CNS Fluid Samples of 11 Patients

\begin{tabular}{|c|c|c|c|c|c|c|}
\hline \multirow[t]{2}{*}{$\begin{array}{l}\text { CSF Parameters } \\
\text { (normal range) }\end{array}$} & \multicolumn{2}{|c|}{$\begin{array}{l}\mathrm{WBC} / \mathrm{mm}^{3} \\
\left(<10 / \mathrm{mm}^{3}\right)\end{array}$} & \multicolumn{2}{|c|}{$\begin{array}{c}\text { Protein (mg/dl) } \\
(15-45 \text { mg/dl) }\end{array}$} & \multicolumn{2}{|c|}{$\begin{array}{l}\text { Glucose }(\mathrm{mmol} / \mathrm{l}) \\
(0.083-3.88 \mathrm{mmol} / \mathrm{l})\end{array}$} \\
\hline & Range & Median & Range & Median & Range & Median \\
\hline Initial puncture & $40-940$ & 60 & $58-650$ & 323 & $0,77-3,02$ & 1,92 \\
\hline First month & $5-160$ & 40 & $68-336$ & 123 & $2,03-3,02$ & 2,66 \\
\hline Third month & $5-40$ & 20 & $40-280$ & 118 & $2,31-2,97$ & 2,67 \\
\hline Sixth month & $5-15$ & 10 & $45-117$ & 110 & $2,47-2,95$ & 2,76 \\
\hline
\end{tabular}

neurobrucellosis, like neurosyphilis, is easily confused with many other neurological, neurosurgical, or even psychiatric disorders. The patients may visit psychiatry departments owing to the chronic character of the disease (15).

Brucellosis is an endemic disease in Turkey and the CNS involvement is reported in $4-11 \%$ of the cases in local studies $(3,13,16,17)$. It seems that to date there is no review in the literature either on the antibiotics currently employed in neurobrucellosis or on the problems related to therapy. Here, we report eleven patients with meningoencephalitis due to Brucella infection and describe the course of the disease to present clues for therapeutic optimization.

\section{Patients and Methods}

Patients who visited Gulhane Military Medical Academy Department of Infectious Diseases and Clinical Microbiology with neurobrucellosis from 2000-2006 are evaluated in this paper.

\section{Diagnosis}

The diagnosis was established by positive serology or isolation of bacteria either in cerebrospinal fluid (CSF) or blood concomitant with abnormal CSF findings (increase in leucocytes and protein, decrease in glucose levels) $(18,19)$ :

a) Abnormal CSF findings included lymphocytes $>10$ / $\mathrm{mm}^{3}$ in CSF with high protein levels (normal range 15-45 $\mathrm{mg} / \mathrm{dl}$ or $0.15-0.45 \mathrm{~g} / \mathrm{l})(20)$ and lower CSF glucose levels (normal range $15-70 \mathrm{mg} / \mathrm{dl}$ or $0.083-3.88 \mathrm{mmol} / \mathrm{l}$ ) (21).

b) Neurological dysfunction not explained by other neurologic diseases.

c) Response to specific chemotherapy with a significant drop in the CSF lymphocyte count and protein concentration.

d) Rose Bengal (RB) agglutination test and standard tube dilution test were the serologic tests performed to detect the presence of brucella antibodies both in blood and CSF.

e) Bactec 9,000 blood culture system was used for the isolation and the classical methods were applied for the identification of bacteria.

\section{Antibiotic doses}

Ceftriaxone $2 \times 2 \mathrm{gr} /$ day intravenously, rifampicin capsules $600 \mathrm{mg} /$ day, doxycycline pills $2 \times 100 \mathrm{mg} /$ day, trimethoprim sulfamethoxazole (SXT) $2 \times 1$ tablets $(160 / 800 \mathrm{mg}$ ) were the preferred antibiotics in the management of neurobrucellosis in the present cases.

\section{CSF analyses}

When a patient was diagnosed as neurobrucellosis in our infectious diseases department, antibiotics are given and the patient was sent home for 2-3 months of rest following the hospitalization necessary for patient stabilization. Thus, all CNS brucellosis patients returned to the military hospital every 2-3 months. On every periodical visit the patient underwent lumbar puncture once again to delineate the status of infection. The biochemical analyses of CNS fluid samples and Wright agglutination test results are presented in Tables 1,2 . Written informed consent for lumbar puncture was obtained from all patients.

\section{Results}

Here we present neurobrucellosis patients (ten males; one female) with an age distribution of 20-55 (29.45 \pm 10.70$)$ years. In Table 1 the biochemical analyses of CSF fluid samples and in Table 2 Wright agglutination test results in are presented.

\section{Short history of the cases}

\section{Case 1}

A 32-year-old female patient had a history of progressive gait disturbance and hearing loss. These complaints had been presented for 2 years when she was first seen in the Neurology Department. Her first neurological examination revealed paraplegia with upper motor neuron signs. MRI showed hyperintense lesions in the brain and contrast enhancement at roots of the lumbosacral region. After CSF analyses, she was given ceftriaxone plus rifampicin combination for two months and therapy for nine months with doxycycline and rifampicin. Her paraplegia did not recover completely in nine months with antibiotics and therapy was extended to 17 months by adding SXT to doxycycline plus rifampicin combination. In this case, bilateral neurosensorial hearing loss was detected with audiometry due to eight cranial nerve involvement and a hearing device was given. She had urinary and fecal incontinence. Although the fecal incontinence improved at the third month of therapy, urinary incontinence partially persisted. Today, that is after 17 
Table 2. The Wright Agglutination Test Results in CSF and Blood during Lumbar Puncture of 11 Patients

\begin{tabular}{|l|c|c|c|c|}
\hline \multirow{2}{*}{ Lumbar puncture } & \multicolumn{2}{|c|}{ CSF } & \multicolumn{2}{c|}{ Blood } \\
\cline { 2 - 5 } & Range & Median & Range & Median \\
\hline Initial puncture & $1 / 100-1 / 600$ & $1 / 200$ & $1 / 200-1 / 800$ & $1 / 800$ \\
\hline First month & $1 / 50-1 / 800$ & $1 / 100$ & $1 / 100-1 / 800$ & $1 / 400$ \\
\hline Third month & $1 / 50-1 / 400$ & $1 / 50$ & $1 / 100-800$ & $1 / 200$ \\
\hline Sixth month & $1 / 50-1 / 100$ & $1 / 50$ & $1 / 100-400$ & $1 / 200$ \\
\hline
\end{tabular}

Table 3. Brief Summary of Neurobrucellosis Patients

\begin{tabular}{|c|c|c|c|c|}
\hline Case & Age & Therapy & Complications & Current status \\
\hline 1 & $32 \mathrm{~F}$ & $\begin{array}{l}\text { CFXN+RIF (2 mo) followed by } \\
\text { SXT+DOXY+RIF (15 mo) }\end{array}$ & $\begin{array}{l}\text { Paraplegia } \\
\text { Bilateral hearing loss } \\
\text { Urinary, fecal incontinence }\end{array}$ & $\begin{array}{l}\text { Infection was eliminated } \\
\text { Urinary incontinence } \\
\text { Could hardly walk }\end{array}$ \\
\hline 2 & $21 \mathrm{M}$ & $\begin{array}{c}\text { DOXY+RIF ( } 2 \mathrm{mo}) \text { followed by } \\
\text { CFXN+RIF }(2 \mathrm{mo}) \text { followed by } \\
\text { DOXY+RIF ( } 2 \text { mo })\end{array}$ & $\begin{array}{l}\text { Spastic paraparesis } \\
\text { Urinary retention }\end{array}$ & Completely cured \\
\hline 3 & $39 \mathrm{M}$ & DOXY+RIF $(6 \mathrm{mo})$ & Bilateral hearing loss & $\begin{array}{l}\text { Infection was eliminated } \\
\text { Hearing loss persisted }\end{array}$ \\
\hline 4 & $21 \mathrm{M}$ & $\begin{array}{c}\text { CFXN+RIF (1 mo) followed by } \\
\text { DOXY+RIF ( } 8 \text { mo })\end{array}$ & $\begin{array}{l}\text { Peripheral neuropathy } \\
\text { Polyradiculopathy } \\
\text { Bilateral hearing loss }\end{array}$ & Completely cured \\
\hline 5 & $20 \mathrm{M}$ & $\begin{array}{l}\text { CFXN+RIF (1 mo) followed by } \\
\text { SXT+DOXY+RIF ( } 5 \mathrm{mo})\end{array}$ & $\begin{array}{l}\text { Subarachnoid hemorrhage } \\
\text { Hydrocephalus }\end{array}$ & $\begin{array}{l}\text { Still in the intensive care } \\
\text { unit }\end{array}$ \\
\hline 6 & $20 \mathrm{M}$ & $\mathrm{SXT}+\mathrm{DOXY}+\mathrm{RIF}$ (6 mo) & Bilateral hearing loss & Hearing loss persisted \\
\hline 7 & $55 \mathrm{M}$ & $\begin{array}{c}\text { DOXY+RIF (1 mo followed by } \\
\text { CFXN+RIF ( } 2 \text { mo }) \text { followed by } \\
\text { DOXY+RIF ( } 3 \text { mo })\end{array}$ & None & Completely cured \\
\hline 8 & $21 \mathrm{M}$ & $\begin{array}{c}\text { CFXN+RIF ( } 2 \text { mo) followed by } \\
\text { DOXY+RIF (4 mo) }\end{array}$ & $\begin{array}{l}\text { Paraparesis } \\
\text { Polyradiculopathy } \\
\text { Could only walk with help }\end{array}$ & $\begin{array}{l}\text { Infections was eliminated } \\
\text { Can hardly walk } \\
\text { unassisted }\end{array}$ \\
\hline 9 & $21 \mathrm{M}$ & $\begin{array}{l}\text { CFXN+RIF ( } 2 \text { mo) followed by } \\
\text { DOXY+RIF (4 mo) }\end{array}$ & None & Completely cured \\
\hline 10 & $20 \mathrm{M}$ & $\begin{array}{l}\text { CFXN+RIF (2 mo) followed by } \\
\text { SXT +DOXY+RIF (4 mo) }\end{array}$ & None & Completely cured \\
\hline 11 & $21 \mathrm{M}$ & $\begin{array}{l}\text { CFXN+RIF (2 mo) followed by } \\
\text { SXT +DOXY+RIF (4 mo) }\end{array}$ & None & Completely cured \\
\hline
\end{tabular}

M: Male, F: Female, Mo: Months

months of finishing antibiotic treatment, she can walk by means of a walker and she has the inability to urinate completely. She has needed to use urinary catheters. Fortunately, her hearing was very normal and she was able to give us the data by means of a telephone; the use of a hearing device was unnecessary six months after discharge.

\section{Case 2}

A 21-year-old male neurobrucellosis patient with spastic paraparesis and urinary retention due to spinal parenchymal involvement was given doxycycline plus rifampicin in another institution. At the second month of therapy his CNS findings worsened. Then, therapy was shifted in our depart- ment to ceftriaxone plus rifampicin combination for an additional two months. The duration of therapy was six months on the whole. At the end of therapy he still had spasticity that did not recess. But the infection was successfully eradicated.

\section{Case 3}

A 39-year-old male patient had bilateral hearing loss detected with audiometry at high frequencies due to eight cranial nerve involvement. After CSF analyses, he was given doxycycline and rifampicin for six months. The infection was eradicated, but his hearing problem was not resolved after nine months of therapy. 


\section{Case 4}

A 21-year-old male patient was suffering from low back pain and weakness and numbness in his legs. His complaints had deteriorated in the previous 3 months. Diminished deep tendon reflexes and distal weakness of the muscles were caused by peripheral neuropathy. Sensory motor polyradiculopathy in the lower extremities due to axonal degeneration was detected with EMG. Bilateral hearing loss was detected. Association of hearing loss and polyradiculopathy let to the clinical diagnosis of neurobrucellosis and CSF and blood examination confirmed the diagnosis. The patient was given ceftriaxone plus rifampicin combination for one month and therapy was completed in nine months with doxycycline plus rifampicin. He recovered with therapy and did not have any sequelae related to walking. His hearing problems were recovered.

\section{Case 5}

A 20-year-old male patient complained of headache, vomiting and fever. After one month of headache, his headache worsened and then fever and vomiting occurred. Neurobrucellosis was diagnosed with CSF examination and he was given ceftriaxone plus rifampicin combination for one month and subsequently SXT, doxycycline and rifampicin combination was used for an additional five months. Subarachnoid hemorrhage occurred at the fourth month of therapy. Ventriculoperitoneal shunt was established because of communicating hydrocephalus. Today he is in the sixth month of therapy, but unfortunately he in a critical situation and is in the intensive care unit of the neurosurgery department.

\section{Case 6}

A 20-year-old male patient had bilateral loss of hearing with audiometric analysis. Since therapy was started outside of our institution as a triple combination with SXT, doxycycline and rifampicin, we continued this regimen for six months on the whole. Although neurobrucellosis was eliminated, his hearing loss persisted.

\section{Case 7}

A 55-year-old male patient presented with weakness, fever and headache. These symptoms had been undulating for 3 weeks. Due to suspicious meningeal irritation signs, lumbar puncture was made and neurobrucellosis was diagnosed. He was initially given doxycycline and rifampicin. At the first month of therapy his CNS findings deteriorated, leukocyte count was elevated and his complaints such as tremor worsened. Then, therapy was shifted to ceftriaxone plus rifampicin combination for an additional two months followed by rifampicin and doxycycline. The duration of therapy was six months on the whole. He did not have any chronic sequelae and completely recovered from the disease.

\section{Case 8}

A 21-year-old male patient had been complaining low back pain, joint pain and fever for one month. Paraparesis and diminished deep tendon reflexes with severe low back pain was the main clinical picture. EMG revealed polyradiculopathy and MRI of the lumbar region demonstrated the contrast enhancement of the lumbar roots. Blood analysis confirmed the diagnosis of Brucellosis. He was given ceftriaxone plus rifampicin for two months followed by rifampicin plus doxycycline for an additional four months. The patient could stand up with help at the second month of antibiotics. At the end of therapy, weakness at the distal ends of lower extremities due to paraparesis was detected. However, the patient could hardly walk by himself. Although rehabilitation programs were recommended, contact was lost with him after discharge.

\section{Case 9}

A 21-year-old male patient was suffering from headache and fever. Due to unknown origin of fever he was referred to our institution. His neurological examination was normal. CSF analysis revealed the diagnosis of neurobrucellosis. He was given ceftriaxone plus rifampicin for two months and the therapy was completed with six months rifampicin and doxycycline. He did not have any complication and recovered completely.

\section{Case 10}

A 20-year-old male patient presented with weakness, fever and headache. He was confused at the first neurological examination. Slight contrast enhancement of meninges on the cranial CT led to LP. Both blood and CSF analysis marked the neurobrucellosis. He was given ceftriaxone plus rifampicin for two months and SXT, doxycycline and rifampicin were given for an additional four months. He had no sequelae and recovered completely.

\section{Case 11}

A 21-year-old male patient presented with a headache to the neurology outpatient department. He was also suffering from fever. His symptoms had been present for 2 weeks. Neck stiffness at the neurological examination required an LP. He was given ceftriaxone plus rifampicin for two months. SXT, doxycycline and rifampicin were given for an additional four months. He also had no sequelae and recovered completely.

$\mathrm{RB}$ test was positive both in the blood and CSF all of the present cases. Brucella melitensis was isolated from the CSF of one case (Case 8) and no pathogen was yielded from the blood cultures. The radiology department did not make any specific contribution in favor of Brucellosis in our cases.

\section{Discussion}

Acute purulent bacterial meningitis (APM) is clinically defined as a syndrome characterized by the onset of meningeal symptoms over the course of hours to up to several days. Headache is a prominent early symptom, often 
followed later by confusion, stupor, or coma. Examination reveals few focal findings early during infection, although signs of meningeal irritation are common. But neurobrucellosis, a form of chronic meningitis, has an onset measured in weeks to months and is generally defined when symptoms, signs, and the CSF remain abnormal for at least 4 weeks (22).

A pooled analysis of adult APM in Turkey revealed that the overall mortality rate was $18 \%$ (23). But, for patients with neurobrucellosis, adequate antibiotic treatment usually is believed to result in a good prognosis (8). The patients with APM in Turkey experienced important sequelae related to pyogenic infection; cranial nerve involvement $(7.7 \%)$, hydrocephalus $(6.4 \%)$, brain abscess $(5.4 \%)$, arthritis $(5.2 \%)$, paralysis $(2.6 \%)$, diplopia $(2.1 \%)$, deafness $(1.9 \%)$ and aphasia (1.7\%) (23). Accordingly, 20-30\% of patients with neurobrucellosis present neurological sequelae. However, these complications are known to be related to the delay in diagnosis and initiation of appropriate antibiotics (8).

Para- or quadriplegia may be one of the atypical presentations of neurobrucellosis and may be due to abscess formation or the chronic sequelae $(24,25)$. One of the present patients had paraplegia (case 1) and she could hardly walk by means of a walker at the end. One patient with spastic paraparesis (case 2) had chronic sequelae and he has difficulty in walking today. In another case with sensory motor polyradiculopathy (case 4) the complications were improved. Finally, one patient had walking difficulty due to axonal degeneration (case 8); although his situation improved, his complaints have not been completely resolved. Consequently, only one of four patients with walking difficulty was completely recovered with ongoing therapy.

It is reported in some case presentations that either defecation or urination problems may be seen in Brucellosis patients with CNS involvement $(25,26)$. One of our patients had both urinary and fecal incontinence (case 1) and another one had (case 2) urinary retention. Fecal incontinence was normalized in due time in the former case. Unfortunately, although urinary problems lessened, they partly persisted in both patients.

Hearing loss was detected (cases 1, 3, 4, 6) in four of our patients. The problem was over in two (cases 1,4) although the complaints were permanent for the other two. This datum validates the understanding that hearing problem is one of the most important problems in neurobrucellosis $(27,28)$. From this point, otologists should consider diagnostic Brucella tests for hearing loss in Brucellosis endemic areas.

Most authorities consider a blood agglutination titer of 1/ 160 or higher in Brucellosis to be significant in a symptomatic patient $(19,29)$ and this is what is performed in Turkish medical practice $(3,30)$. But the issue of neurobrucellosis is a little bit different than brucellosis on the whole since the diagnosis is often delayed and difficult as the signs and symptoms may be overt or subtle $(2,4)$. Normally the specific diagnosis is based upon seroagglutination and cultures, which have relatively low sensitivities $(10,31)$. The finding of Brucella specific antibodies in the CSF is highly indicative of CNS infection; however, since these antibodies are sometimes present at low levels, agglutination tests commonly employed in the diagnosis of neurobrucellosis may give false-negative results $(32,33)$. Moreover, controversy exists on the optimization of CSF antibody levels. In our study, all the initial blood titers were lower than 1/200 and the CSF titers were under $1 / 100$ on initial examination. All of the cases in our study had positive CSF serology. Does that mean that some the cases with negative results are missed? Unfortunately, this may be the case. From this perspective, it is important to focus on CNS investigation and not ignore the neural component of the disease or the use of novel diagnostic technology, if possible, should be indicated since molecular-based methods appear to be promising (34). Furthermore, awareness of the existence of the disease is essential since appropriate diagnostic tests and therapeutic interventions, if carried out in timely fashion, may save lives.

Another subacute or chronic meningitis syndrome, neurotuberculosis, presents with a CSF formula characterized by lymphocytic pleocytosis, lowered glucose concentration, and a high protein content (35). CNS tuberculosis accounts for about one percent of all cases of tuberculosis and six percent of all extrapulmonary infections in immunocompetent individuals (36). Neurotuberculosis includes three clinical categories: meningitis, intracranial tuberculoma, and spinal tuberculous arachnoiditis. All three forms of CNS infection are encountered frequently in regions of the world where the incidence of brucellosis is high (37). Careful evaluation for CNS tuberculosis and brucellosis is warranted in the patient suspected of any of these probable diagnoses.

Imaging abnormalities reflect inflammatory or demyelinating processes or a vascular insult and do not always correlate with the clinical picture. So, neurobrucellosis may mimic any other infectious or inflammatory conditions (38). This was the same in the present cases and all of the radiological findings were nonspecific.

The management of neurobrucellosis requires special attention since the illness is potentially life threatening and conventional antibiotics used in the management of CNS infections like penicillin, chloramphenicol, cephalosporins, carbapenems or the antiviral agents are ineffective. Most authorities recommend the combination of two or three drugs which cross the blood-brain-CSF barrier (such as doxycycline, rifampicin, trimethoprim-sulfamethoxazole, ciprofloxacin, ceftriaxone) $(8,31,39)$. Treatment needs to be individualized according to signs and symptoms but should generally be continued until the CSF analysis has returned to normal. That is, the duration of therapy is individualized and is generally prolonged, varying from 1 to 19 months $(8,31,39)$. In four of our cases oral antibiotics were given (cases 2, 3, 6, 7) and the situation became worse in two of these cases. Although the data related to the routine use of ceftriaxone in CNS brucellosis is lacking in the literature, therapy was modified with parenteral ceftriaxone in these patients and subsequently the disease was clearly re- 
solved. Furthermore, ceftriaxone was given initially for one month in two cases and for two months in five patients. No clinical dilemma from the point of infectious diseases was seen in these cases and the infection was successfully eradicated.

It is known that untreated neurobrucellosis has high mortality and morbidity (40). None of our patients died, albeit one case has a critical situation due to subarachnoid hemorrhage that may potentially lead to mortality. Consequently, the use of parenteral antibiotics as an initial component of therapy followed by long-term sequential oral antibiotics seems important in the management of neurobrucellosis. In addition, the absence of parenteral therapy appears to result in therapeutic failure. Moreover, according to CSF analyses and clinical follow-up in our study, approximately six months of antibiotic therapy in neurobrucellosis seems adequate.

\section{References}

1. Godfroid J, Cloeckaert A, Liautard JP, et al. From the discovery of the Malta fever's agent to the discovery of a marine mammal reservoir, brucellosis has continuously been a re-emerging zoonosis. Vet Res 36: 313-326, 2005.

2. Young EJ. Brucella Species. In: Mandell, Bennett, \& Dolin: Principles and Practice of Infectious Diseases. 6 ed. Mandell GL, Douglas RG, Bennett JE, Eds. Churchill Livingstone, Philadelphia, 2005: 2670-2673.

3. Sözen TH. Brucellosis. In: İnfeksiyon Hastalıkları ve Mikrobiyolojisi. 2 ed. Topçu AW, Söyletir G, Doğanay M, Eds. Nobel Tip Kitabevleri, Istanbul, 2002: 636-641 (Textbook section in Turkish).

4. Young EJ. Overview of Brucellosis. Clin Infect Dis 21: 283-289, 1995.

5. Mantur BG, Mangalgi SS, Mulimani M. Brucella melitensis-a sexually transmissible agent? Lancet 347: 1763, 1996.

6. Smits HL, Kadri SM. Brucellosis in India: a deceptive infectious disease. Indian J Med Res 122: 375-384, 2005.

7. Colmenero JD, Reguera JM, Martos F, et al. Complications associated with Brucella melitensis infection: a study of 530 cases. Medicine (Baltimore) 75: 195-211, 1996.

8. McLean DR, Russell N, Khan MY. Neurobrucellosis: clinical and therapeutic features. Clin Infect Dis 15: 582-590, 1992.

9. Pappas G, Papadimitriou P, Akritidis N, Christou L, Tsianos EV. The new global map of human brucellosis. Lancet Infect Dis 6: 91-99, 2006.

10. Shakir RA, Al-Din AS, Araj GF, Lulu AR, Mousa AR, Saadah MA. Clinical categories of neurobrucellosis. A report on 19 cases. Brain 110 (Pt 1): 213-223, 1987.

11. Solera J, Martinez-Alfaro E, Espinosa A. Recognition and optimum treatment of brucellosis. Drugs 53: 245-256, 1997.

12. Samdani PG, Patil S. Neurobrucellosis. Indian Pediatr 40: 565568, 2003.

13. Yüce A, Alp-Çavuşlu S, Yapar N, Çakır N. Brucellosis: Evaluation of 55 case. (article in Turkish). Klimik Derg 19: 13-7, 2006.

14. Şencan İ, Bahtiyar Z, Yazıcı Y. A case of lumbar epidural abscess due to Brucellosis which mimics disk hernia. İnfeks Derg 18: 113-115, 2004 (in Turkish).

15. Ersöz-Arat M, Karsen H, Bakırcı A, Akdeniz H. A case of neurobrucellosis with coma. Klimik Derg 219: 36-37, 2006 (in Turkish).

16. Cesur S, Çapar Y, Demir P, et al. Retrospective evaluation of 104 cases with Brucellosis. İnfeks Derg 18: 169-173, 200 (in Turkish).

17. Geyik MF, Kökoğlu ÖF, Hoşoğlu S, Ayaz C. The evaluation of 154 patients with Brucellosis. Dicle Tip Derg 29: 23-29, 2002 (in Turkish).

18. Heper Y, Yılmaz E, Akalın H, Mıstık R, Helvacı S. Neurobrucellosis: evaluation of 9 cases. Klimik Derg 17: 99-102, 2004 (article in Turkish).

19. Kochar DK, Kumawat BL, Agarwal N, et al. Meningoencephalitis in brucellosis. Neurol India 48: 170-173, 2000.
20. DeMott J. Immunology: cerebrospinal fluid protein. In: Laboratory Test Handbook. 5 ed. Lexi-Comp, Inc, Hudson, Cleveland, 2001: 517.

21. Demott J. Chemistry: Cerebrospinal fluid glucose. In: Laboratory Test Handbook. 5 ed. Lexi-Comp, Inc, Hudson, Cleveland, 2001: 140.

22. Tunkel AR, Scheld WM. Acute Meningitis. In: Principles and Practice of Infectious Diseases. 6 ed. Mandell G, Bennett J, Dolin R, Churchill Livingstone, Philadelphia, 2005: 1084-1126.

23. Arda B, Sipahi OR, Atalay S, Ulusoy S. Pooled analysis of 2,408 cases of acute adult purulent meningitis from Turkey. Med Princ Pract 17: 76-79, 2008.

24. Hesseling AC, Marais BJ, Cotton MF. A child with neurobrucellosis. Ann Trop Paediatr 23: 145-148, 2003.

25. Keihani-Douste Z, Daneshjou K, Ghasemi M. A quadriplegic child with multiple brain abscesses: case report of neurobrucellosis. Med Sci Monit 12: CS119-CS122, 2006.

26. Vajramani GV, Nagmoti MB, Patil CS. Neurobrucellosis presenting as an intra-medullary spinal cord abscess. Ann Clin Microbiol Antimicrob 4: 14, 2005.

27. Cagatay A, Karadeniz A, Ozsut H, Eraksoy H, Calangu S. Hearing loss in patient with neurobrucellosis. South Med J 99: 13051306, 2006.

28. Thomas R, Kameswaran M, Murugan V, Okafor BC. Sensorineural hearing loss in neurobrucellosis. J Laryngol Otol 107: 10341036, 1993.

29. Malik GM. A clinical study of brucellosis in adults in the Asir region of southern Saudi Arabia. Am J Trop Med Hyg 56: 375-377, 1997.

30. Tümtürk A, Yetkin MA, Tülek N, Kılıç D. The value of serum aglutination test and enzyme linked immunosorbent assay IgM and IgG antibodies to Brucella in diagnosis and follow-up of Brucellosis. Klimik Derg 17: 107-112, 2004 (in Turkish).

31. Bouza E, Garcia de, la Torre M, Parras F, Guerrero A, RodriguezCreixems M, Gobernado J. Brucellar meningitis. Rev Infect Dis 9: 810-822, 1987.

32. Baldi PC, Araj GF, Racaro GC, Wallach JC, Fossati CA. Detection of antibodies to Brucella cytoplasmic proteins in the cerebrospinal fluid of patients with neurobrucellosis. Clin Diagn Lab Immunol 6: 756-759, 1999.

33. Sanchez-Sousa A, Torres C, Campello MG, et al. Serological diagnosis of neurobrucellosis. J Clin Pathol 43: 79-81, 1990.

34. Colmenero JD, Queipo-Ortuno MI, Reguera JM, Baeza G, Salazar JA, Morata P. Real time polymerase chain reaction: a new powerful tool for the diagnosis of neurobrucellosis. J Neurol Neurosurg Psychiatry 76: 1025-1027, 2005.

35. Erdem HA, Aksoy B, Kilıc S, et al. Profiles of biochemical parameters in central nervous system fluid during the therapeutic courses of adult Mycobacterium tuberculosis meningitis. Scand J Infect Dis 38: 710-712, 2006.

36. CDC. CDC reported tuberculosis in the United States. US Department of Health and Human Services. 2004 September 2005. 
37. al-Deeb SM, Yaqub BA, Sharif HS, Motaery KR. Neurotuberculosis: a review. Clin Neurol Neurosurg 94 (Suppl) : S30-S33, 1992.

38. Al-Sous MW, Bohlega S, Al-Kawi MZ, Alwatban J, McLean DR. Neurobrucellosis: clinical and neuroimaging correlation. AJNR Am J Neuroradiol 25: 395-401, 2004.

39. Akdeniz H, Irmak H, Anlar O, Demiröz AP. Central nervous sys- tem brucellosis: presentation, diagnosis and treatment. J Infect 36: 297-301, 1998.

40. Kochar DK, Agarwal N, Jain N, Sharma BV, Rastogi A, Meena CB. Clinical profile of neurobrucellosis-a report on 12 cases from Bikaner (north-west India). J Assoc Physicians India 48: 376-380, 2000

(C) 2008 The Japanese Society of Internal Medicine http://www.naika.or.jp/imindex.html 